\title{
Democracia Digital no Brasil: mapeamento e análises de artigos publicados em PERIÓDICOS ENTRE 1999-20181
}

\author{
Rafael Cardoso Sampaio² \\ Christiana Soares Freitas ${ }^{3}$ \\ Nilton Cesar Monastier Kleina ${ }^{4}$ \\ Djiovanni Jonas França Marioto ${ }^{5}$ \\ Bruno Washington Nichols ${ }^{6}$ \\ Tiago Philippini Ferreira Borges da Silva ${ }^{7}$ \\ Murilo Brum Alison ${ }^{8}$ \\ Gabriel Alexandre Bozza ${ }^{9}$ \\ Victor Hausen ${ }^{10}$
}

\section{INTRODUÇÃO}

A popularização da internet comercial e a maior oferta de computadores pessoais significaram uma maior atenção acadêmica voltada a temas que relacionam participação, engajamento cívico, serviços e equipamentos para comunicações digitais on-line. Essas reflexões indicam a importância das implicaçôes políticas e sociotécnicas dos recursos tecnológico-informacionais para regimes democráticos e tecnologias. Por suas características que fomentam a comunicação - inclusive direta, entre cidadãos e elite política - e pela quebra do polo de emissão, as diversas plataformas e ferramentas digitais foram vistas como passíveis do fomento de uma ideia de democracia digital, transcendendo distâncias políticas e constituindo interaçóes (Coleman e Blumler, 2009; Gomes, 2011) entre as mais diferentes esferas. Em certo momento, significou também a digitalização de toda a democracia, e mesmo o questionamento de o que a internet poderia fazer por ela (Gomes, 2016). Nesse sentido, a retórica da democracia digital (ou e-democracia) se constrói: por um lado, temos índices de participação civil em queda e desconfiança da elite política por parte dos eleitores, que se isolam cada vez mais de seus representantes, ocasionando certa crise de legitimidade do sistema político e suas decisóes (Gomes, 2011); por outro, temos uma plataforma que surgiu com a promessa de revolucionar a forma como as pessoas se relacionam e se comunicam.

Desse modo, identificamos uma narrativa sobre e-democracia em que as tecnologias funcionam, de forma predominante, para sanar os problemas de legitimidade, trazendo os representantes para mais perto dos representados ou possibilitando maior participaçáo política por parte dos cidadãos (Coleman e

1. DOI: http://dx.doi.org/10.38116/bapi25art2

2. Professor do Departamento de Ciência Política da Universidade Federal do Paraná (UFPR).E-mail: <cardososampaio@gmail.com>.

3. Professora do Departamento de Políticas Públicas da Universidade de Brasília (UnB).E-mail: <freitas.christiana@gmail.com>.

4. Doutorando do Programa de Pós-Graduação em Comunicação (PPGCOM) da UFPR.E-mail: <nckleina@gmail.com>.

5. Mestrando do Programa de Pós-Graduação em Ciência Política (PPGCP) da UFPR.E-mail: <djiovannimarioto@gmail.com>.

6. Doutorando do PPGCP-UFPR.E-mail:<brunonichols@outlook.com>.

7. Mestrando do PPGCP-UFPR. E-mail: <tpfbsilva@gmail.com>.

8. Mestrando do PPGCP-UFPR.E-mail:<murilo43@hotmail.com>.

9. Doutorando do PPGCP-UFPR.E-mail: <gabrielbozz@gmail.com>.

10. Graduando em ciências sociais pela UFPR.E-mail: <hausen.victor@gmail.com>. 
Blumler, 2009; Freitas, Lima e Lima, 2015). Dessa forma, pode-se entender a democracia digital como a utilização de tecnologias de informação e comunicação (TICs) visando promover avanços de valores democráticos ou ainda facilitar atividades democráticas. Com ela, espera-se fortalecer a relação entre os cidadãos e seus representantes, porém admitindo que a participação não seja o único caminho para esse fim. Assim, embora reconheçamos que não exista um consenso sobre o que significa democracia digital (Simon et al., 2017), compreendemos nesse conceito qualquer uso de dispositivos, aplicativos ou ferramentas digitais de comunicação "para suplementar, reforçar ou corrigir aspectos das práticas políticas e sociais do Estado e dos cidadãos em benefício do teor democrático da comunidade política” (Gomes, 2011, p. 28-29). ${ }^{11}$

Devido à carência de estudos bibliográficos e cientométricos específicos da temática em diferentes áreas, este trabalho representa um esforço em desenvolvimento de uma ampla pesquisa que busca analisar o que foi produzido sobre democracia digital nos periódicos científicos brasileiros. Para tanto, mapeamos e analisamos 347 artigos publicados em periódicos brasileiros entre 1999 e 2018 sobre o assunto, com base em estudos anteriores (Sampaio, Bragatto e Nicolás, 2016; Sampaio et al., 2018) sobre internet e política (I\&P).

\section{METODOLOGIA}

A coleta foi realizada por meio de um script usando Selenium - ferramenta de teste de sistemas web a fim de coletar as páginas dos resultados de busca do Google Scholar, que depois foram processadas com BeautifulSoup para extrair a URL das páginas das revistas e outros metadados que o portal disponibiliza na página de resultado. Essa busca foi realizada por meio de múltiplas pesquisas com as principais palavras-chave utilizadas pelo campo. ${ }^{12}$ Logo após, esse processo foi revisado com o acréscimo de outras palavras-chave detectadas nos artigos iniciais. ${ }^{13}$

O Google Scholar foi escolhido para tentar compreender a transdisciplinaridade do campo. Ademais, conforme evidenciado na pesquisa de Mugnaini et al. (2019), 60\% dos periódicos nos quais os pesquisadores brasileiros publicam não estão indexados na SciELO, no Scopus ou no Web of Science. Um dos critérios de inclusão e exclusão de trabalhos foi o processo de revisão por pares (peer review process), visando manter apenas artigos publicados em periódicos. Além desse fato, foram analisados apenas artigos, uma vez que estes se tornaram o principal formato de comunicaçáo científica, sendo mais numerosos e especializados. O recorte temporal foi definido a partir de 1999 por ser este o momento em que surgem os primeiros artigos sobre internet e política (Sampaio, Bragatto e Nicolás, 2016).

Em seguida, os artigos foram analisados manualmente a partir da análise de conteúdo (Neuendorf, 2001), tendo o livro de códigos de pesquisa anterior (Sampaio et al., 2018) como base, sendo realizadas pequenas

11. Duas coletâneas recentes parecem abordar os principais temas e objetos da democracia digital no Brasil: Mendonça, Pereira e Filgueiras (2016) e Silva, Bragatto e Sampaio (2016).

12. As palavras-chave iniciais foram: "edemocracia", "democracia digital", "democracia eletrônica", "democracia virtual", "democracia online", "democracia AND novas mídias", "democracia AND tecnologia", "ciberdemocracia", "teledemocracia" "democracia AND Internet", "eparticipação", "participação AND tecnologia", "participação AND Internet", "participação AND digital", "participação AND virtual", "participação AND TICs", "participação AND novas mídias", "participação AND online", "participação política online", "participação política digital", " participação política virtual" "edeliberação", "deliberação AND Internet", "deliberação AND digital", "deliberação virtual", "deliberação online", "esfera pública \& internet", "esfera pública \& digital", "esfera pública virtual", "esfera pública online", "etransparência" "transparência digital", "transparência AND novas mídias", "transparência online", "transparência AND internet", "Transparência AND tecnologia", "Transparência AND TICs", "transparência AND websites", "Transparência AND portais".

13. Foram acrescentadas: "governo aberto", "dados abertos governamentais", "parlamento aberto", "parlamento digital", "webcidadania", "exclusão digital", "governo aberto", "dados abertos governamentais", "parlamento aberto", "parlamento digital", "webcidadania", "esfera pública \& internet", "esfera pública \& digital", "esfera pública virtual", "esfera pública online", " governança eletrônica" , "governança digital", "governança da internet", "governança algorítmica", "regulação algorítmica" e "tecnopolítica". 
adaptaçóes. ${ }^{14} \mathrm{O}$ objetivo foi identificar as principais características dos autores (nome, sexo, instituição, quantidade de participantes, escolaridade, área de atuaçáo e eventuais parcerias), dos artigos (ano e periódico), da abordagem (vertente, seja social ou institucional; objeto político; objeto tecnológico; abordagem teórica) e questóes sobre os métodos empregados (empírico ou teórico; método; técnica de pesquisa; e uso de estatística). Tais variáveis foram selecionadas por comporem quadros teórico-metodológicos de pesquisas anteriores e, dada a proximidade do objeto, serão utilizados como base para análise e comparação (Sampaio, Bragatto e Nicolás, 2016; Sampaio et al., 2018).

O processo foi capaz de identificar 2.146 trabalhos acadêmicos. Um dos problemas do Google Scholar é indexar excessivos repositórios, alguns inclusive pouco acadêmicos. Houve, portanto, uma filtragem manual realizada pelos pesquisadores do grupo, baseada no conceito de democracia digital. ${ }^{15}$ Após a retirada manual de artigos repetidos, falsos positivos ${ }^{16}$ e de trabalhos que não eram artigos acadêmicos (isto é, capítulos, papers de eventos, dissertaçóes e teses), identificamos 347 trabalhos referentes a estudos ou reflexóes sobre o tema em periódicos científicos brasileiros.

\section{RESULTADOS INICIAIS}

Percebe-se que os artigos sobre democracia digital ganham força entre 2009 e 2012, com um novo pico de crescimento em 2015, conforme mostra o gráfico 1. Entretanto, a partir desse período, as publicaçóes na área apresentam inconstâncias.

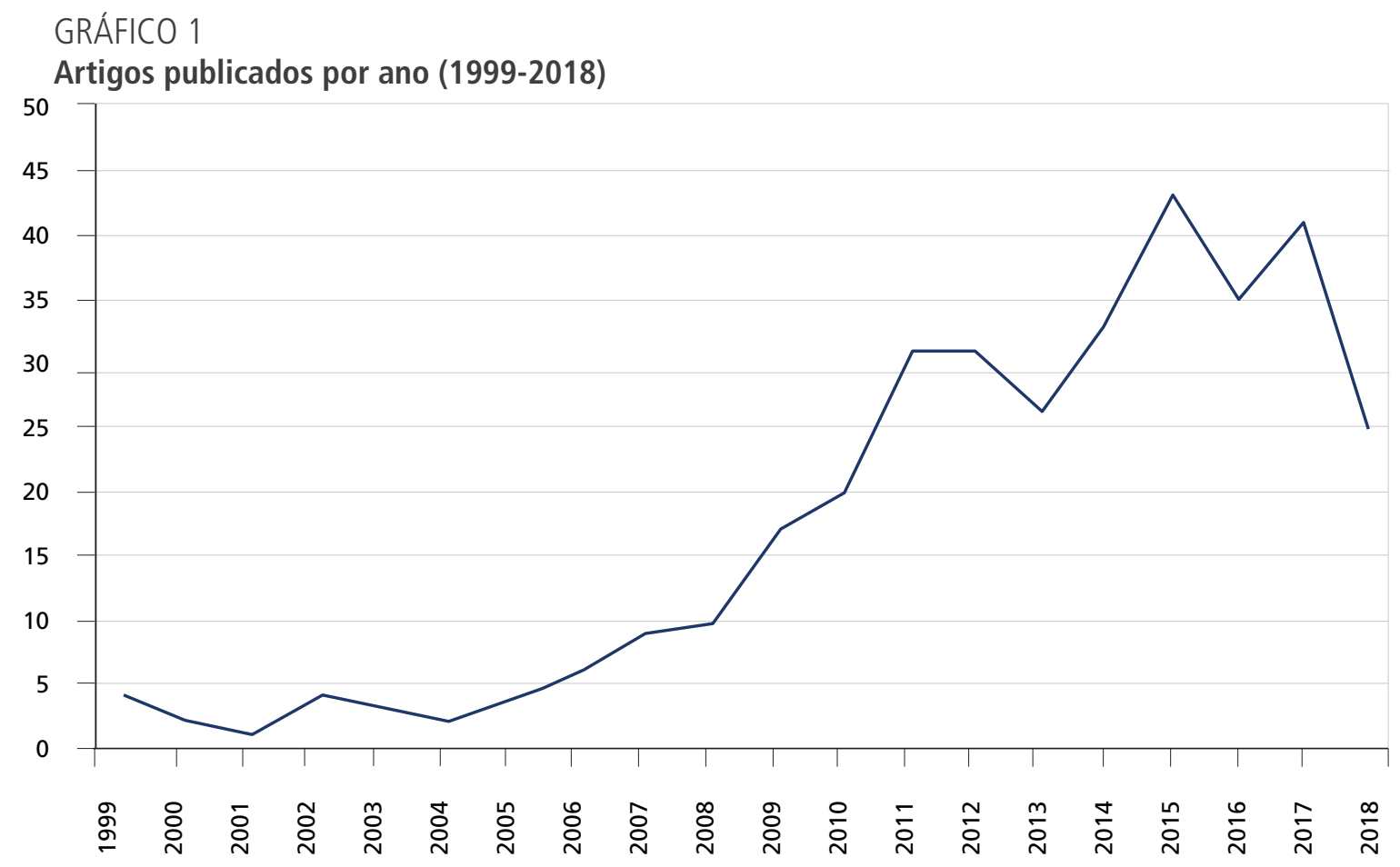

Elaboração dos autores.

14. Disponivel em: <https://drive.google.com/file/d/1cUPMdrCH71qUlebiwpTOFKtMc7YINtz_/view>. Acesso em: 18 jun. 2020.

15. 0 processo da filtragem manual foi feito a partir da leitura integral de todos os documentos encontrados, utilizando a definição de Gomes (2011) sobre o conceito de democracia digital como critério de inclusão; desse modo, excluímos os artigos que não se encaixavam.

16. Podemos considerar como falsos positivos os artigos que não faziam parte do escopo da democracia digital e revistas estrangeiras, principalmente as portuguesas. 
Os dados iniciais, por ora baseados exclusivamente no primeiro autor de cada artigo, revelam que as universidades com maior produção são Universidade Federal da Bahia (UFBA) (n=39), Universidade Federal do Paraná (UFPR) ( $\mathrm{n}=35)$, Universidade Federal de Minas Gerais (UFMG) ( $\mathrm{n}=28)$, Universidade de São Paulo (USP) $(\mathrm{n}=17)$ e Universidade de Brasília (UnB) ( $\mathrm{n}=13$ ), sendo que ainda temos o aparecimento da Universidade Estadual Paulista (UNESP) (n = 15) e da Universidade Federal de Santa Maria (UFSM) $(n=12)$ de um total de 110 instituiçóes com, ao menos, um trabalho publicado em periódico científico sob as temáticas pesquisadas. $\mathrm{O}$ gráfico 2 mostra que a comunicação segue como a área com maior presença na pesquisa sobre democracia digital, estando a ciência política em segundo lugar, com administração e ciências sociais ocupando lugares de destaque, e o campo de direito como terceira força.

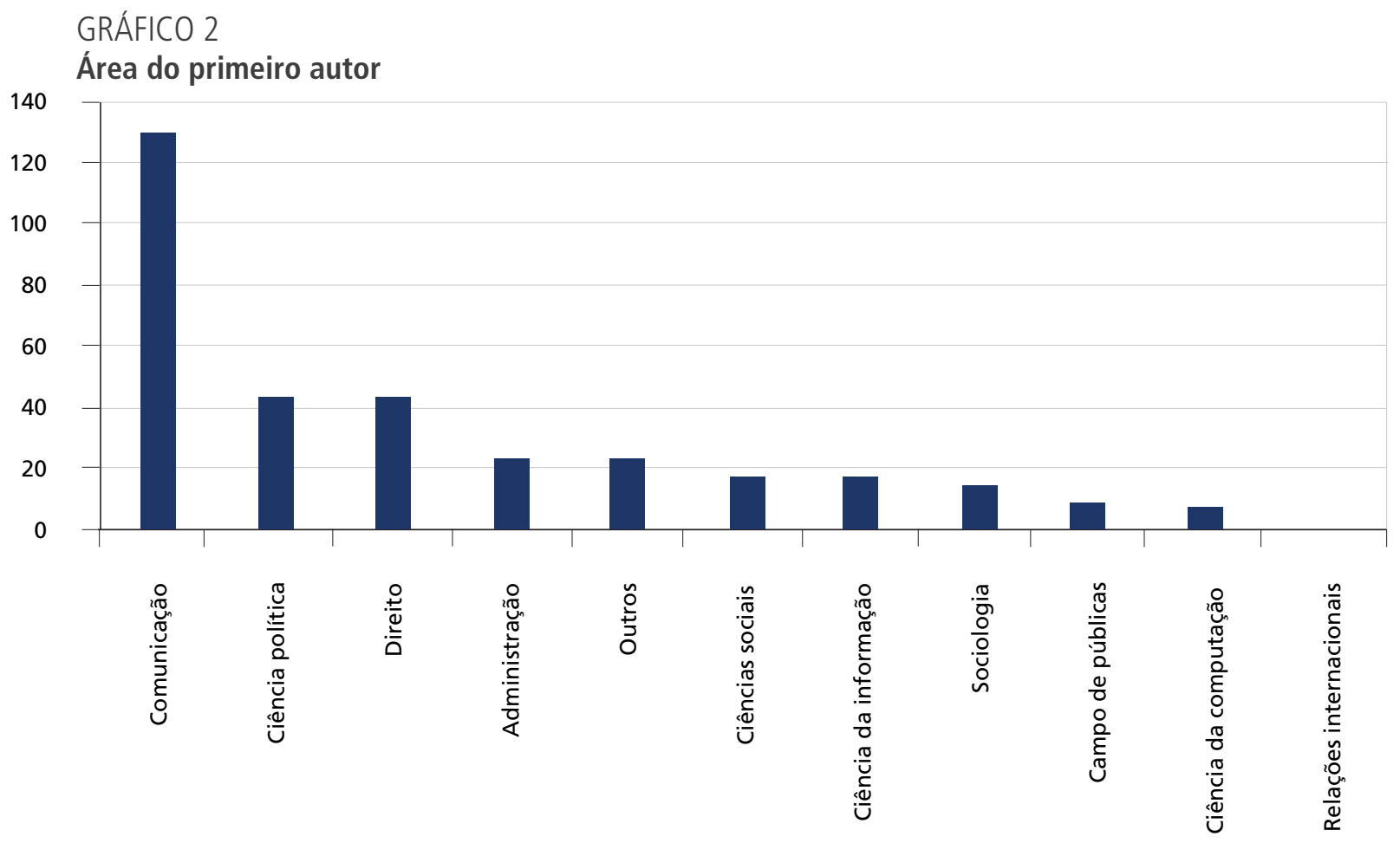

Elaboração dos autores.

As revistas dividiram-se de maneira semelhante. Ao todo, foram catalogados 190 periódicos, sendo que 67 destes contêm ao menos dois artigos. A revista Democracia Digital e Governo Eletrônico $\mathrm{da}$ área do direito foi a que mais recebeu trabalhos (12), seguida pela revista Compolítica $(\mathrm{n}=10)$, da área de comunicação e política. A comunicação esteve representada em maior número também pelas revistas Fronteiras $(\mathrm{n}=5)$, Intexto $(\mathrm{n}=5)$ e Contemporânea $(\mathrm{n}=5)$. Foram identificados artigos de ciência política nos periódicos Opiniáo Pública $(\mathrm{n}=8)$, Revista de Sociologia e Politica $(\mathrm{n}=6)$, Revista $\operatorname{USP}(\mathrm{n}=4)$ e Revista Eletrônica de Ciência Politica ( $\mathrm{n}=4)$. A Revista de Administração Pública $(\mathrm{n}=6)$ e Organizaçóes \& Sociedade $(\mathrm{n}=5)$ são as mais frequentes nos periódicos de administração.

Neste primeiro momento, trabalhamos apenas com os dados do primeiro autor ou da primeira autora de cada artigo. Identificamos 248 autores(as) ao todo, sendo que 44 aparecem em mais de uma revista. Entre os primeiros, 130 são do sexo masculino e 148 do sexo feminino. Seguindo estudos vistos anteriormente em internet e política (Sampaio, Bragatto e Nicolás, 2016; Sampaio et al., 2018), 
a maioria dos autores é doutor $(50,1 \%)$, seguida por doutorandos $(21,2 \%)$, mestrandos $(11,3 \%)$ e mestres (11\%). Graduados e graduandos, juntos, representaram 5,1\% do total - uma divisão coerente com normas de submissão de diversos periódicos nacionais que tendem a restringir a participação de pesquisadores no período de mestrado ou graduação ou, ainda, exigindo a presença de um doutor entre coautores. Quando são observados todos os autores dos artigos, a maioria não apresenta parceria interinstitucional (63\%) e nem interdisciplinar (63,9\%), evidenciando uma baixa colaboração entre pesquisadores de diferentes áreas e universidades.

A respeito das abordagens, observa-se, inicialmente, um claro equilíbrio entre a vertente social $(49,3 \%)$ e a institucional $(50,7 \%)$. Esses resultados ficam mais nítidos quando verificamos o gráfico 3, que trata dos principais objetos políticos estudados pela democracia digital brasileira.

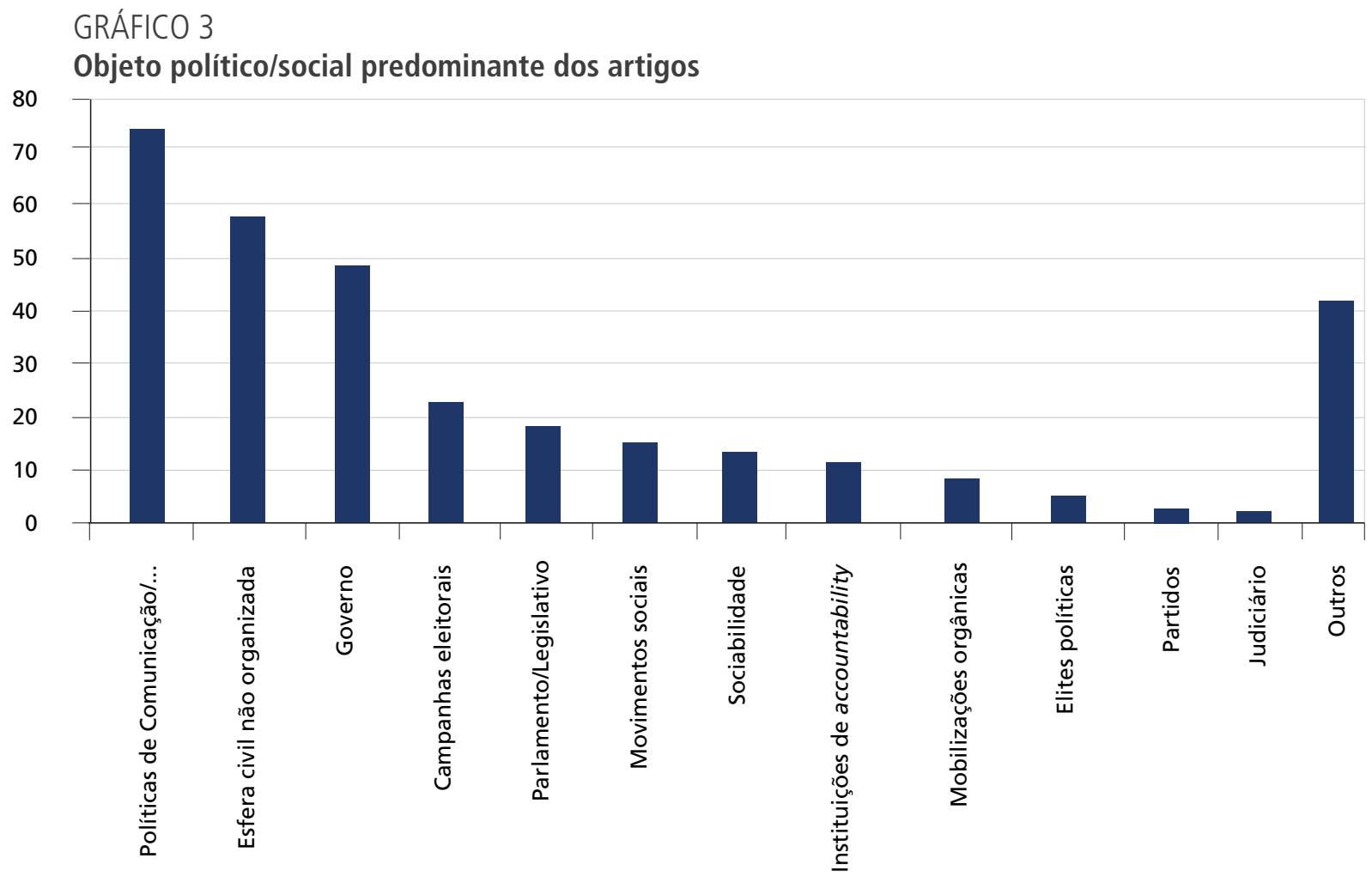

Elaboração dos autores.

No gráfico 3, as categorias esfera civil não organizada, governo e movimentos sociais aparecem nos primeiros lugares. Chama a atenção o primeiro lugar de políticas de comunicação/economia política - tema não apontado como relevante nos estudos de Sampaio, Bragatto e Nicolás (2016) e Sampaio et al. (2018). Uma hipótese para o fato é a entrada de campos como administração e direito no corpus da pesquisa. Como neste estudo definimos objetos mais específicos, especializados, fica evidente a importância dos estudos sobre parlamentos digitais $(n=19)$ e como o Judiciário continua como o poder menos visitado pela democracia digital.

Os dados apresentados vão ao encontro daqueles expostos em Sampaio, Bragatto e Nicolás (2016), no que diz respeito ao objeto tecnológico principal do artigo. O principal objeto é uma reflexão mais ampla sobre a internet, algo mais visto nos primeiros artigos da área. Em seguida, 
puxados pelos artigos de transparência e participação, temos os websites. Mídias sociais são o terceiro objeto mais visitado pela democracia digital, conforme apresentado no gráfico 4 .

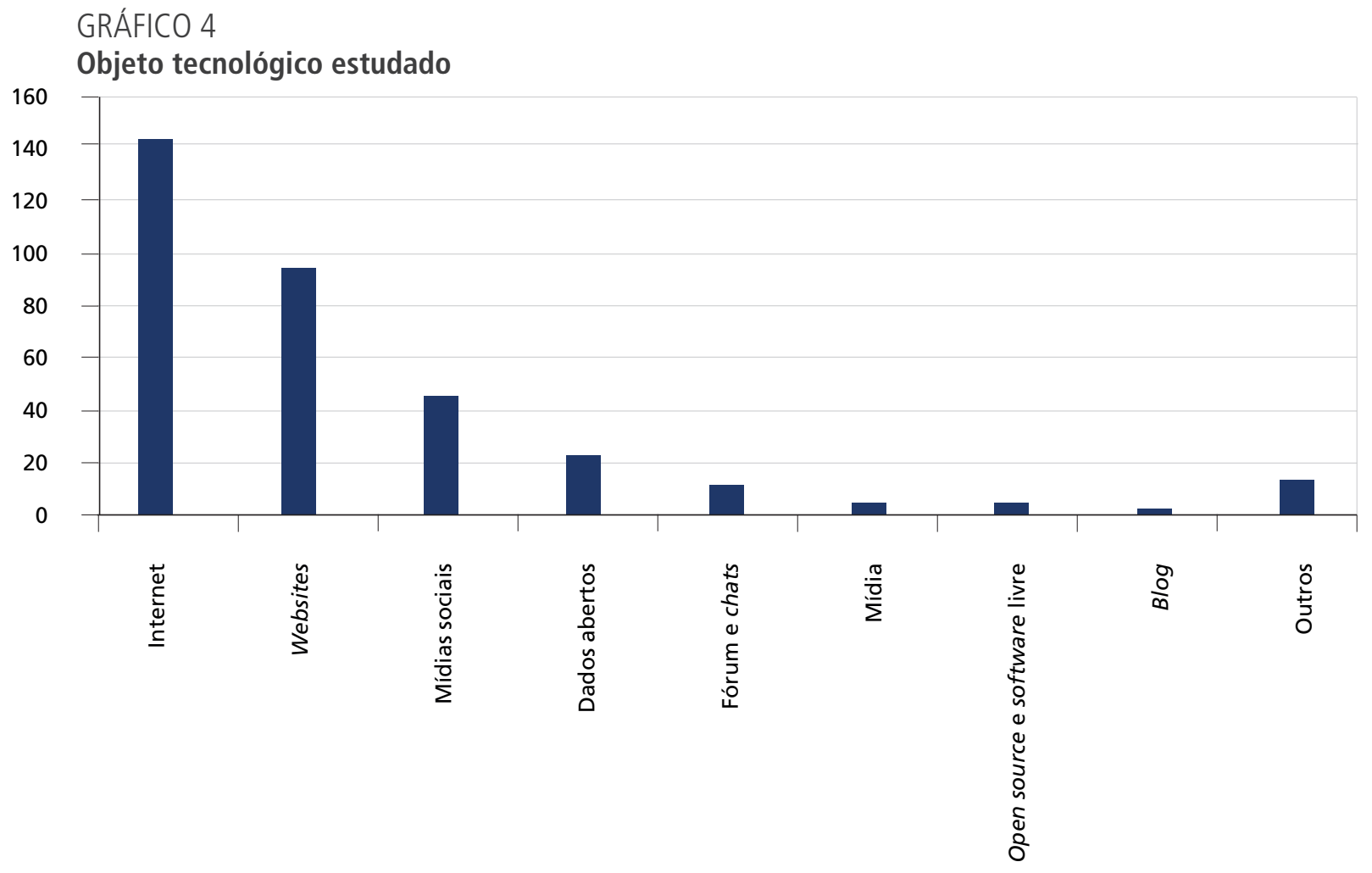

Elaboração dos autores.

Tentando avançar um pouco em relação aos dados dos estudos anteriores, buscamos justamente verificar quais as mídias sociais mais estudadas e se comprovou o esperado: Facebook é a rede digital mais estudada $(n=25)$, seguida por YouTube $(n=7)$ e Twitter $(n=5)$.

Seguindo tanto o padrão das pesquisas brasileiras sobre internet e política e sobre democracia digital e governo eletrônico quanto o padrão internacional da pesquisa sobre democracia digital (Gomes, 2016), as três principais abordagens teóricas majoritariamente utilizadas são participação $(n=72)$, transparência $(n=69)$ e deliberação $(n=52)$, conforme mostra o gráfico 5 . Neste estudo, acrescentamos a opção da abordagem teórica sobre a própria democracia digital, que esteve presente em 43 artigos. Nota-se, ainda, que a teoria da economia política e das políticas de comunicação é pouco acionada ou não é predominante nos estudos, mesmo sendo o objeto político mais presente nos artigos catalogados.

Concluímos, ainda, que a maior parte dos artigos $(\mathrm{n}=205)$ apresentou estudos empíricos $(59,1 \%)$, enquanto 142 artigos (40,9\%) foram teóricos. Entre os empíricos, a maioria fez uso de métodos qualitativos (44,3\%), depois métodos quantitativos (29,2\%), seguidos por métodos mistos (quanti/quali) (17,5\%). Ainda, 8,7\% fizeram uso do método bibliográfico. A análise de conteúdo foi a técnica mais acionada, estando presente em $60 \%$ das pesquisas, enquanto a análise heurística esteve em $18,5 \%$, seguida por análise documental (6,3\%), análise do discurso $(4,8 \%)$ e surveys $(2,9 \%)$. 


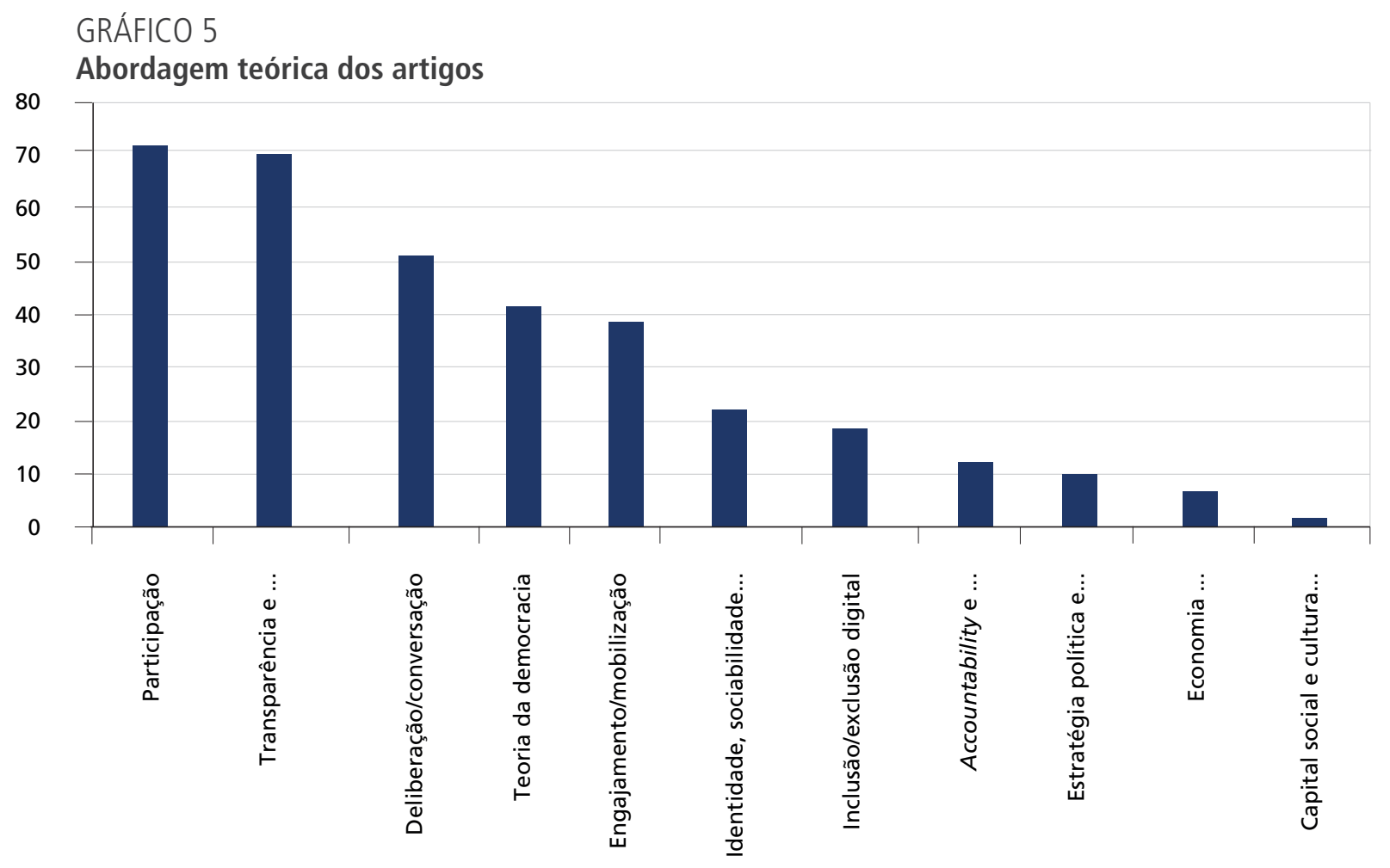

Elaboração dos autores.

Do total de artigos empíricos, 116 fizeram uso de algum tipo de estatística, contra 89 que não o fizeram. Não obstante, repetindo o padrão já visto em Sampaio, Bragatto e Nicolás (2016) e Sampaio et al. (2018), a grande maioria dos trabalhos que utilizaram estatística $(n=90)$ lidaram apenas com frequência simples, totalizando 77,5\% dos artigos empíricos. A estatística univariada foi utilizada em seis artigos, enquanto a estatística bivariada esteve presente em vinte estudos, o que representa $17,2 \%$ dos estudos empíricos.

O nosso resultado reforça o achado de Sampaio, Bragatto e Nicolás (2016), que já denotavam uma curta gama de opçóes de técnicas de pesquisa e de uso de estatística nas pesquisas do campo de I\&P, algo também verdadeiro para a democracia digital.

\section{CONSIDERAÇÕES FINAIS}

A partir da análise de periódicos do campo de democracia digital no Brasil, algumas observaçóes podem ser tecidas/elaboradas. É notável que a literatura de democracia digital apresenta, de forma geral, características muito próximas da literatura de internet e política (Sampaio, Bragatto e Nicolás, 2016; Sampaio et al., 2018) e do campo da comunicação e política. A pesquisa interdisciplinar, portanto, gerou poucas alteraçóes nos resultados, o que pode ser um indicativo de que a democracia digital é naturalmente um objeto predominante dessas áreas. Uma surpresa foi a entrada do direito como área de alta presença no corpus, algo que não havia sido detectado nos estudos anteriores. Esse fato revela a falta de transdisciplinaridade da área, uma vez que estudos a respeito de eventos de comunicaçãa, ciências sociais e de administração não identificaram rastros sobre a produçáo em direito. Isso indica que o acréscimo de eventos e periódicos dessa área podem trazer interessantes resultados em pesquisas futuras. 
Após o ápice em 2015, o número de artigos publicados por ano vem caindo. Sugere-se o desenvolvimento de pesquisas futuras no sentido de corroborar a hipótese que indica tendência à perda de interesse na área ou uma migração para outras temáticas. Futuros estudos podem comparar tais dados com aqueles mais gerais de internet e política para verificar a questão, porém, é possível que os pesquisadores estejam migrando para temas e objetos mais próximos ao cotidiano da política (real politics).

Sobre as universidades, o lugar de destaque de UFBA, UFPR, UFMG, UnB e Universidade Federal Fluminense (UFF) coincide com os achados de pesquisas anteriores. Contudo, a USP aparece como a quarta universidade com mais produção, algo pouco detectado em outros estudos. É provável que a dispersão de áreas de pesquisa na democracia digital permita que a USP tenha artigos das mais diferentes áreas e galgue lugar de importância na pesquisa no geral.

Entretanto, ao que tudo indica, existe uma fragmentação das pesquisas quando verificamos os periódicos. O fato de termos 347 artigos divididos em mais de 190 periódicos é exemplo disso, assim como a percepção generalizada de um excessivo número de revistas acadêmicas similares no Brasil. A iminência de periódicos de comunicação e ciência política confirma como a democracia digital é majoritariamente produzida por pesquisadores desses campos.

Ao contrário da literatura sobre I\&P, identificamos maior presença da vertente institucional sobre a social. Nota-se, portanto, alto interesse por iniciativas e estratégias governamentais, além de políticas de comunicaçáo. À semelhança de I\&P, pesquisadores de democracia digital analisaram mais a internet como um todo, em menor escala, verificando websites e mídias sociais. Mais raro ainda foi a identificação de estudos sobre plataformas sociais específicas, como o Facebook. Conforme visto na literatura brasileira de I\&P e na internacional de democracia digital (Gomes, 2016), as principais abordagens teóricas são de participação, transparência, deliberação e teoria da democracia digital. A maioria dos artigos baseia-se em estudos empíricos, e, como na literatura de I\&P, a maior parte utiliza a análise de conteúdo. Da mesma maneira, quando havia alguma análise estatística, a maioria das pesquisas lidou apenas com frequências simples.

Os resultados evidenciam que a democracia digital parece representar uma parte bastante significativa dos estudos mais amplos entre internet e política, ressaltando a importância da temática especialmente no campo da comunicação e política. Não obstante, diferente de trabalhos anteriores sobre I\&P, nota-se que direito, administração e políticas públicas apresentam suas próprias contribuiçôes na discussão sobre democracia digital. Portanto, em alguma medida, mais que um campo de pesquisa, temos uma temática que perpassa três áreas que pouco dialogam entre si. A falta de interdisciplinaridade, que já ocorria nos eventos de I\&P, repete-se nos periódicos científicos. Isso se deve, provavelmente, aos incentivos da Coordenação de Aperfeiçoamento de Pessoal de Nível Superior (CAPES) para a publicaçáo em periódicos da área de atuaçáo de cada pesquisador. Entretanto, isso gera uma lacuna em termos de colaboração acadêmica e acúmulo de conhecimento científico.

Como reflexão final, especialmente no momento em que os estudos sobre democracia digital parecem estar em retração (seja pelo contexto ou pela migraçáo para estudos em política digital), a pesquisa sobre democracia digital poderia avançar, consideravelmente, a partir de esforços no sentido de conformação de um campo de pesquisa de fato. Enquanto é normal e esperado que cada área de origem possa ter uma contribuição mais específica no campo, parece-nos que mais trocas acadêmicas poderiam levar a consideráveis ganhos em termos teóricos e, especialmente, metodológicos. 


\section{REFERÊNCIAS}

COLEMAN, S.; BRUMLER, J. The internet and democratic citizenship: theory, practice and policy. Cambridge: Cambridge University Press, 2009.

FREITAS, C.; LIMA, F.; LIMA, F. Os desafios ao desenvolvimento de um ambiente para participação política digital: o caso de uma comunidade virtual legislativa do projeto e-Democracia no Brasil. Organizaçóes \& Sociedade, v. 22, n. 75, p. 639-657, 2015.

GOMES, W. Participação política online: questões e hipóteses de trabalho. In: MAIA, R. C. M.; GOMES, W.; MARQUES, F. P. J. A. (Org.). Internet e participaçáo política no Brasil. Porto Alegre: Sulina, 2011. p. 19-45.

. 20 Anos de Política, Estado e Democracia Digitais: uma cartografia do campo. In: SILVA, S.; BRAGATTO, R.; SAMPAIO, R. (Org.). Democracia digital, comunicaçáo política e redes: teoria e prática. Rio de Janeiro: Letra \& Imagem, 2016. p. 39-76.

MENDONÇA, R.; PEREIRA, M.; FILGUEIRAS, F. (Org.). Democracia Digital: publicidade, instituições e confronto político. Belo Horizonte: Editora UFMG, 2016.

MUGNAINI, R. et al. Panorama da produção científica do Brasil além da indexação: uma análise exploratória da comunicação em periódicos. Transinformaçáo, v. 31, 2019.

NEUENDORF, K. The content analysis guidebook. Londres: Sage, 2001.

SAMPAIO, R.; BRAGATTO, R.; NICOLÁS, M. A construção do campo de internet e política: análise dos artigos brasileiros apresentados entre 2000 e 2014. Revista Brasileira De Ciência Política, v. 4, p. 285-320, 2016.

SAMPAIO, R. et al. Ciberpolítica, Ciberativismo e Cibercultura: uma análise dos papers apresentados no grupo de trabalho da ANPOCS. BIB - Revista Brasileira de Informaçáo Bibliográfica em Ciências Sociais, v. 85, p. 126-147, 2018.

SILVA, S.; BRAGATTO, R.; SAMPAIO, R. (Org.). Democracia digital, comunicaçáo política e redes: teoria e prática. Rio de Janeiro: Letra \& Imagem, 2016.

SIMON, J. et al. Digital Democracy: the tools transforming political engagement. London: Nesta, 2017. 
